\title{
Solar HDH Desalination for Coastal Hotels: Literature Review and Research Trend
}

\author{
Danilo Barahona-Pike1, a, Victoria Posas-Medina1, b, Ronal Pérez-Alvarado1, c, Edgar Ramos ${ }^{1, d}$, and Cesar Humberto \\ Ortega-Jimenez ${ }^{1,2,3, ~ e, ~ f, ~ g ~}$
}

\author{
'Universidad Nacional Autónoma de Honduras (UNAH), Facultad de Ingeniería, Ingeniería Mecánica, Tegucigalpa, Honduras \\ ${ }^{2}$ Universidad de Sevilla, Doctorado GENI, Sevilla, Spain \\ ${ }^{3}$ Universidad Tecnológica Centroamericana (UNITEC), Facultad de Postgrado, Honduras \\ adanilo.barahona@unah.hn, ${ }^{\mathrm{b}}$ victoria.posas@unah.hn, ${ }^{\mathrm{c}}$ ronal.perez@unah.hn, ${ }^{\mathrm{d}}$ edgar.ramos@unah.hn, ${ }^{\mathrm{e}} \mathrm{cortega} @ u n a h . e d u . h n$,
} fcortega@us.es, ${ }^{9}$ cortegaj@unitec.edu

\begin{abstract}
Water is essential for the hotel industry, its disposition is key to ensure the viability of the tourism sector that grows disproportionately day by day plus the scarcity of water in the world, this situation forces hotels to find alternatives to meet the demand for water. One of the preferred alternatives is solar water desalination. The purpose of this paper is to demonstrate through this first literature review whether solar desalination is a viable technique to meet the demand of potable water in a medium-sized hotel in a coastal area. We conducted a review of the literature published between 1987 and 2018, the subject of which is solar HDH desalination. Inclusion and exclusion criteria were formulated and applied to determine the most relevant studies to achieve the purpose of this research. The review found that solar desalination can be feasible to apply in hotels if they have large amounts of land for installation or the demand for water is not large. However, there are more economic methods to desalinate water while at the same time producing more water with similar sizes of facilities. Such results have practical implication for the use of the systems of hotels in general.
\end{abstract}

\section{Introduction}

Over the past 50 years, global water consumption has increased significantly[1].The hotel industry is not immune to this situation, especially since it ranks as the largest industry in terms of international trade, and continues to grow day by day[2]. Consequently, due to the increasing demand of water in this industry, solar desalination seems to be the most suitable solution to solve this problem in coastal areas because this areas have abundant seawater and sunlight [3]. One of the most preferred method for small scale application in remote areas is solar desalination by the humidification and dehumidification (HDH), because the cost of fabrication, operation and maintenance are lower than other desalination techniques [4-5]. Several researches have been conducted to research the solar desalination $\mathrm{HDH}$, some of such literature will be illustrated in the following paragraph. Firstly, in 1998 Farad and Al-Hallaj built an HDH desalination unit in Iraq. This unit collected $12 \mathrm{~L} / \mathrm{d}$ per $\mathrm{m}^{2}$ from a single solar collector, which meant an improvement compared to previous research, showing only a single solar basis under the same conditions[6]. It is worth mentioning Ben Bacha et al, they presented a comprehensive research models, simulations and experimental validation of HDH systems, which aid the development of future improvements in the system [7]. In addition, Joo and Kwak built a multi-effect small-scale optimized unit, they concluded that the average performance of the unit was 2.0 [8]. Another significant improvement can be found in Riffat and Mayere paper, in their research, they used a V-shaped hub, increasing the thermal efficiency to $38 \%$, when the water temperature reached $100{ }^{\circ} \mathrm{C}$ at the output of this hub. Hence, they concluded that the $\mathrm{V}$ shaped concentrator is a promising application for solar desalination [9]. In the research of Houcine et al., it was used a pilot plant with five stages and a total collector area of $127 \mathrm{~m}^{2}$, it was achieved an output of $4 \mathrm{~L} / \mathrm{m}^{2}$ daily [10].

A restraint in the production was found in Kheder work made, in which they concluded by a techno-economic investigation, that $\mathrm{HDH}$ has potential only for plants that are below 10 cubic meter per day [11]. Also important was the research of Nafey shows a production of $9 \mathrm{~L} / \mathrm{m}^{2}$ daily [3], while Muller-Holst's resulted in $13 \mathrm{~L} / \mathrm{m}^{2}$ a day [12]. Although there is literature about $\mathrm{HDH}$ solar desalination, no papers were found regarding its application in the hotel industry to supply water consumption. Therefore, we sought to answer the following research question: whether the HDH system may be feasible in the production of fresh water to meet the demand for water in hotels? Our study makes a comprehensive review of the current experimental literature, and state of the art of the HDH system. Seeking to respond to such research question, focused on the following two objectives: (1) to verify if the application of

Corresponding author: ${ }^{\mathrm{e}}$ cortega@unah.edu.hn 
$\mathrm{HDH}$ technology is viable for hotels in coastal areas; and (2) to determine if the size requirements for such technology does not exceed $50 \mathrm{~m}^{2}$, taking to account the state of the art of the system. Thus, the structure of this paper is as follows: In Section 2, the frame of reference and propositions are presented. In Section 3, the methodology is detailed. Then, in Section 4 analysis are made and the results are discussed. Finally, Section 5 presents the conclusions of the research

\section{Related work}

There are many technologies to desalinate water, such as are reverse osmosis, multi effect distillation and multi flash stage desalination [13]. Among them, the HDH technology is a system based on the air's characteristics, by being able to charge a greater quantity of water when raising its temperature. In the HDH system, the air is brought into contact with saltwater (previously heated in the solar heater) inside the humidifier, where it obtains latent heat and water vapor. This air is then put in contact with a cooling surface (cooled by medium of the saltwater that is subsequently heated) in the dehumidifier; the result of the condensation is the fresh water that is then stored in a tank [1]. Its basic system consists of packed towers, energy absorber, pumps, fans and heat exchangers [2]. However, there are several improvements and variations to the basic system $[2,4]$. The humidification dehumidification process works as moisture content of air increases progressively with elevated temperature [38]. The simplest form of the HDH process Fig. 1 consists of three subsystems: (a) air and/or water heater, which can use various sources of heat, such as solar, thermal, or combinations of these; (b) humidifier or evaporator; and (c) dehumidifier or condenser [24,28,32].

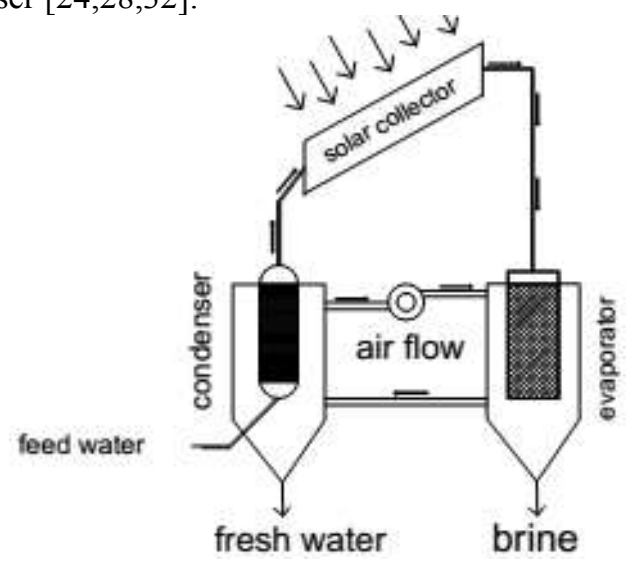

Fig.1. Schematic diagram of HDH system.

Further, HDH systems are classified under three main broad categories[34]: (1) type of circulation; (2) type of heating; and (3) type of circulation loop. A comparison of 12 systems was made, where 8 systems, the simplest form of the HDH process, two of them present a cogeneration, one by hybrid humidification-dehumidification water desalination and air conditioning system and the remaining 4 have HDH systems have been called "multi -effect humidification "(MEH) where the heat can be used many times to produce vapor. In order to establish a framework for the $\mathrm{HDH}$ system to be implemented in the hotel industry, it is necessary to delimit it from the wide variety of configurations, plant sizes, and system improvements available in the literature. To do this, we mainly based the framework from three important publications from leading authors in the specialized literature, Shani, Housine et al. and Nafey et al., since they made some of the most thorough investigations and significant improvements on the system in recent years [4,10-11]. Muller-Holst et al.'s [13] research is also key for the application in question, since its improvement does not depend on large sizes to produce more water. Therefore, their research is also used as point of reference to determine the feasibility of the system, considering its size and water production, which is measured in liters per day. It was also a key point of this investigation to determine the water demand found in hotels. The water in the hotels can be used in many ways depending on the hotel or resort, such as irrigation, toilets, showers, laundry, and even swimming pools, among other things [8]. In Hawaii, for example, where the hotel industry is responsible for $30 \%$ of the state's income, water consumption can vary between 38,000 and one million liters of water per year [9]. The estimation is that only one room may have a consumption of 300 liters per day for each of these hotels [10].

Going further in the use that can be given to desalinated water, we cite what S. Duranceau explained on page 1 of his work: "desalinated water is considered corrosive because of its inherently low mineral content and may not be suitable for consumption without adequate post-treatment [11]. Hence, human consumption in hotels from such kind of water would imply an additional system to make it suitable for consumption. However, such additional system for potable water are beyond the scope of this paper. Hence, we will stay on focus on the use that can be given to water that is not going to be ingested or does not have direct contact with humans. Due to the corrosive quality of the produced water, it has been decided to not consider its application in laundry, since there may be damage done to the clothes, by untreated water, leaving its uses for toilets and irrigation. Therefore, considering the framework presented in this section; the following two propositions are made. First, based on the information found about the production of the $\mathrm{HDH}$ system, we propose:

Proposition 1: the HDH system meets the water demand of a medium size hotel

Making use of the reference about the different improvements that have been made on this system, which are aimed at obtaining a greater volume of desalinated water, we make the second proposition:

Proposition 2: the HDH system is as economically competitive, as other desalination processes such as reverse osmosis, multi-effect distillation and desalination multi flash stage.

\section{Methodology}

The study by Newbert [13] and Sanahuaja [14], was used as a guideline for carrying out this research where seven steps were developed. After defining our research goals 
and question, we started with the first step, we selected the databases to find the most relevant studies of the subject. The databases chosen were Scopus, Science direct and EBSCOhost. In the second step, the selection of keywords was made. "HDH", "humidification dehumification", "solar desalination" were chosen to obtain results according to the theme and thus diminish existing biases. In the third step, the time interval was defined. The selected period was from 1987 to 2018 to analyze the advances in technology. The fourth step focused on the inclusion and exclusion criteria, we include only journal articles and conference papers and exclude thesis, books and manuals. We only include papers that were written in English and remove those in other language. This strategy produced the following number of papers: 95 of Scopus/Science Direct, 10 of EBSCOhost. Then the number of documents to analyze was reduced using the fifth step) including a combination of secondary keywords: water desalination. The result was 56 papers. Thereby, we proceeded to read the summaries, to reduce redundancies (sixth step) and considering only the relevant documents. Finally, we got 18 papers of science direct/Scopus, 4 of EBSCOhost. To complete it, a manual search of other documents was made using complementary databases: Research Gate and Google Scholar, adding three papers. As a result, 25 relevant articles were admitted carrying out the review. Then to track and manage the found documents, we used Mendeley.

\section{Results, analysis and discussion}

The results of this review cover a total of 25 articles, Fig. 2 illustrates a summary of the articles reviewed, it shows most of the papers are articles from science direct, Scopus and EBSCOhost. Table 1 shows the main journals that were involved in this Research, were most journal cited were Desalination (SJR Q1, 1.96), Energy conversion and management (SJR Q1 2.54) and Energy Procedia (SRJ $0.49)$.

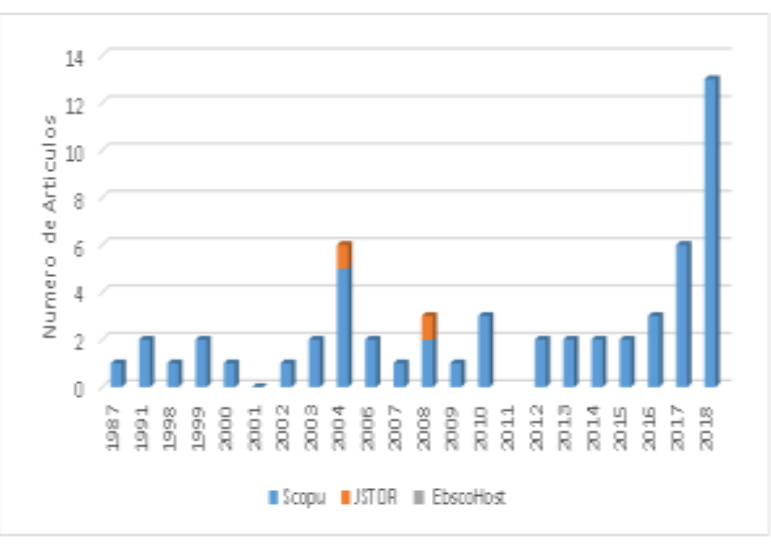

Fig. 2. Summary of the results.

Table.1. Journals involved in the research.

\begin{tabular}{|l|c|c|c|}
\hline \multicolumn{1}{|c|}{ Journal } & Citations & SJR & H-index \\
\hline Renewable Energy & 2 & Q1, 1.85 & 143 \\
\hline Renewable and Sustentable Energy Reviews & 1 & Q1, 3.04 & 193 \\
\hline Process Safety and Enviroment Proteccion & 1 & Q1, 0.80 & 52 \\
\hline Proceedings of the ASME Disign Engineerinng T. & 1 & NA, 0.14 & 41 \\
\hline Procedia Engineerinng & 1 & NA, 0.28 & 40 \\
\hline Journal of Environmenntal Management & 1 & Q1, 1.16 & 131 \\
\hline Journal of Cleaner Production & 1 & Q1, 1.47 & 132 \\
\hline International Journal of Hydrogen Energy & 1 & Q1, 1.12 & 173 \\
\hline Energy Procedia & 2 & NA, 0.49 & 56 \\
\hline Energy Conversion and Management & 2 & Q1, 2.54 & 147 \\
\hline Energy & 1 & Q1, 1.99 & 146 \\
\hline Desalination and Water Treatment & 1 & Q2, 0.40 & 40 \\
\hline Desalination & 11 & Q1, 1.96 & 139 \\
\hline
\end{tabular}

The first proposition pursued by this literature review is to check whether the HDH System can meet the total or partial water demand of a medium size hotel, which according to the research has about 120 rooms [8-9]. Thus, the review showed Table. 2 states that this technique is only viable if the hotel's water demand is small or the hotel owns vast amount land to install the plant and increase the production of water. The papers in the Table $3[12,19$, 20-35] respond to the proposal in a negative way. A. Cipollini states that this method is used in areas where they require a short demand of water [15]. While Delyannis states that the method is appropriate for capacities less than 70 cubic meters per day but if more water is required, they another recommend to use other technology [16].
Gorjian also supports that this method should be applied in regions where the demand does not exceed 200 cubic meters per day[17]. The results obtained on the size of the desalination plant emphasize that large amounts of land are required. This coincided with Semiat, this investigation stated that the collecting surface area should be about 250 square meters just to produce 1 cubic meters of potable water per day [18]. Likewise, the results obtained regarding the production of solar desalination plants show that they do not produce quantities greater than $20 \mathrm{~L}$ per day. This agrees with what, Yamali and Solmuş[19],Houcine et al.[10] , Nafey [3], Muller-Holst et al. [12] and Farid [6], all agree that the productivity of this method is among 4 and $13 \mathrm{~L}$ per square meter of water per day. 
Table 2. Summary of the productivity of HHD desalination systems.

\begin{tabular}{|l|l|l|c|}
\hline Authors & Year & Results & Reference \\
\hline Ashrafizadeh and Amidpour & 2012 & The productivity of the unit was found to be $0.0059[\mathrm{~kg} / \mathrm{s}]$ & {$[24]$} \\
\hline El-Agouz & 2010 & The productivity of the unit was found to be $8.22[\mathrm{~kg} / \mathrm{d}]$ & {$[25]$} \\
\hline Wang et al. & 2012 & The productivity of the unit was found to be $30.873\left[\mathrm{~kg} / \mathrm{m}^{2} \mathrm{~d}\right]$ & {$[26]$} \\
\hline Hermosillo et al. & 2012 & The productivity of the unit was found to be $1.45[\mathrm{~kg} / \mathrm{h}]$ & {$[27]$} \\
\hline Farsad and Behzadmehr & 2011 & The productivity of the unit was found to be $27[\mathrm{~kg} / \mathrm{h}]$ & {$[28]$} \\
\hline Amer et al. & 2009 & The productivity of the unit was found to be $5.8[\mathrm{~L} / \mathrm{h}]$ & {$[29]$} \\
\hline Zhani and Ben Bacha & 2010 & The productivity of the unit was found to be $21.75[\mathrm{~kg} / \mathrm{d}]$ & {$[30]$} \\
\hline Muthusamy et al. & 2014 & The productivity of the unit was found to be $0.82[\mathrm{~kg} / \mathrm{h}]$ & {$[31]$} \\
\hline Kabeel et al. & 2014 & The productivity of the unit was found to be $23.6[\mathrm{~kg} / \mathrm{h}]$ & {$[32]$} \\
\hline Yamali and Solmus & 2007 & The productivity of the unit was found to be $4\left[\mathrm{~L} / \mathrm{m}^{2}\right.$ per day] & {$[19]$} \\
\hline Muller-Holst et al. & 1998 & The productivity of the unit was $13[$ L/m per day $]$ & {$[12]$} \\
\hline Semiat & 2000 & The collecting area surface requires to be around $250\left[\mathrm{~m}{ }^{2}\right]$ & {$[18]$} \\
\hline Cipollina & 2014 & The productivity of the units was $100[\mathrm{~L}$ per day $]$ & {$[15]$} \\
\hline Houcine et al. & 2006 & The productivity of the unit was found to be $4\left[\mathrm{~L} / \mathrm{m}^{2}\right.$ per day] & {$[10]$} \\
\hline Nafey & 2004 & The productivity was $9[\mathrm{~kg} / \mathrm{s}] \mathrm{L} /$ day & {$[3]$} \\
\hline
\end{tabular}

Table 3. Summary of the cost productivity of HHD desalination systems.

\begin{tabular}{|l|l|l|c|c|}
\hline Authors & Year & Results & Reference \\
\hline Tzen and Morris & 2003 & The cost of water produced was found to be in the range of 1.50€-5.00€ per [ $\left.\mathrm{m}^{3}\right]$ & {$[20]$} \\
\hline Karagiannis and Soldatos & 2008 & The cost of water produced was found to be in the range of 2.50€-6.30€ per [ $\left.\mathrm{m}^{3}\right]$ & {$[22]$} \\
\hline Avlonatis & 2002 & The cost of water produced was found to be in the range of 3.20€-8.00€ per [ $\left.\mathrm{m}^{3}\right]$ & {$[21]$} \\
\hline Alkaisi,Mossad & 2017 & The cost of water preoduction can vary 2.40€ $-6.19 €$ per $\left[\mathrm{m}^{3}\right]$ & {$[23]$} \\
\hline
\end{tabular}

The second proposition of this review deal on whether the HDH system is as economically competitive as desalination by reverse osmosis, multi-effect distillation and multistage flash desalination. As before, the review also rejects such proposition. Considering mainly with what Tzen[20],Avlonitis [21], Karagiannis[22] and Alkalis [23] in the Table 2, agree that the cost of water production, using solar desalination technology is between $€ 3.14-€ 9$ per $m^{3}$. This means at least more than three times the cost of other process such as multi stage flash(MSF), whose cost oscillates between $0.42 €-1.01 €$ per $m^{3}$, or multi effect (MED) with cost varying between $0.76 €-1.95 €$ per $m^{3}$, or the cost of water produced with reverse osmosis (RO) that varies between $0.26 €-0.35 €$ per $m^{3}$. This leads us to assert that the HDH system is not competitive toward other desalination technologies.

\section{Conclusions}

Based on the results of the investigation the application of the HDH system in hotels exceeding 200 rooms is not recommended. In addition, since there is dependence of the $\mathrm{HDH}$ system for big facilities to produce big amounts of water, we conclude that it may not be convenient for most industries and is not currently a convenient solution for obtaining fresh water in communities with a limited space. The production of water could be increased doubling or tripling the size of the installation, but even so, it would not be enough to satisfy the water demand in a significant way, given that the production is linked to the size of the solar collector. Such limitation may be an opportunity for future research on its application to small hotels (30 rooms). Further, alternative technologies to desalinate may be reviewed in future research. For instance, Reverse Osmosis and MSF (plant requires large dimensions) show some of the lowest production costs among desalination technologies $[1,16]$.

Finally, since this paper presents in this literature review on HDH solar desalination in hotels in coastal areas. The practical and methodological implications are important, since prior to this paper, Bouroni's statement of whether the HDH system was useful in hotels [2], was considered true, and now an opportunity to carry out future research in the HDH system innovation and/or its potential application to other markets, or for alternative technologies, is now available.

\section{Acknowledgments}

The authors wish to acknowledge the support of UNAH.

\section{References}

1. J.-P. Ceron et al., "Tourism and Water Use: Supply, Demand and Security-An International Review Sustainable Geo-Resources for Tourism and Recreation View project Progress in Tourism Management Tourism and water use: Supply, demand, and security. An international review," 2012.

2. A. Pombo, A. Breceda, and A. V. Aragón, "Desalinization and Wastewater Reuse as Technological Alternatives in an Arid, Tourism Booming Region of Mexico," Frontera Norte, vol. 20, no. 39, pp. 191-216, 2008.

3. A. S. Nafey, H. E. S. Fath, S. O. El-Helaby, and A. M. Soliman, "Solar desalination using humidification dehumidification processes. Part I. A numerical investigation," Energy Conversion and Management, vol. 45, no. 7-8, pp. 1243-1261, May 2004.

4. H. Kim et al., "RENEWABLE RESOURCES Water harvesting from air with metal-organic frameworks 
powered by natural sunlight Downloaded from," 2017.

5. S. M. Shalaby, M. A. Bek, and A. E. Kabeel, "Design Recommendations Humidification-dehumidification Solar Water Desalination Systems," Energy Procedia, vol. 107, pp. 270-274, Feb. 2017.

6. N. Kh Nawayseh, M. Mehdi Farid, S. Al-Hallaj, and A. Rahman Al-Timimi, "Solar desalination based on humidification process-I. Evaluating the heat and mass transfer coefficients," Energy Conversion and Management, vol. 40., no.13, pp. 1423-1439, 1999.

7. H. B. Bacha, M. Bouzguenda, M. S. Abid, and A. y. Maalej, Modelling and simulation of a waterdesalination station with solar multiple condensation evaporation cycle technique, Renewable Energy, vol. 18, no. 3. pp. 349-365, 1999.

8. H.-J. Joo and H.-Y. Kwak, "Performance evaluation of multi-effect distiller for optimized solar thermal desalination," Applied Thermal Engineering, vol. 61, no. 2, pp. 491-499, Nov. 2013.

9. S. Riffat and A. Mayere, "Performance evaluation of v-trough solar concentrator for water desalination applications," Applied Thermal Engineering, vol. 50, no. 1, pp. 234-244, Jan. 2013.

10. I. Houcine, M. BenAmara, A. Guizani, and M. Maâlej, "Pilot plant testing of a new solar desalination process by a multiple-effect-humidification technique," Desalination, vol. 196, no. 1-3, pp. 105-124, Sep. 2006.

11. M. Khedr, "Techno-Economic investigation of an air humidification-dehumidification desalination process," Chemical Engineering \& Technology, vol. 16, no. 4, pp. 270-274, Aug. 1993.

12. H. Müller-Holst, M. Engelhardt, and W. Schölkopf, "Small-scale thermal seawater desalination simulation and optimization of system design," Desalination, vol. 122, no. 2-3, pp. 255-262, Jul. 1999.

13. Z. Chang, H. Zheng, Y. Yang, Y. Su, and Z. Duan, "Experimental investigation of a novel multi-effect solar desalination system based on humidification-dehumidification process," Renewable Energy, vol. 69, pp. 253-259, Sep. 2014.

14. S. A. Ashrafizadeh and M. Amidpour, "Exergy analysis of humidification-dehumidification desalination systems using driving forces concept," Desalination, vol. 285, pp. 108-116, Jan. 2012.

15. S. Farsad and A. Behzadmehr, "Analysis of a solar desalination unit

with humidification-dehumidification cycle using DoE method," Desalination, vol. 278, no. 1-3, pp. 70-76, Sep. 2011.

16. A. E. Kabeel, M. H. Hamed, Z. M. Omara, and S. W. Sharshir, "Experimental study of a humidification-dehumidification solar technique by natural and forced air circulation," Energy, vol. 68, pp. 218-228, Apr. 2014.

17. Y. Ghalavand, M. S. Hatamipour, and A. Rahimi,
"Humidification compression desalination," Desalination, vol. 341, pp. 120-125, May 2014.

18. H. Ettouney and M. Wilf, "Commercial Desalination Technologies," 2009, pp. 77-107.

19. S. L. Newbert, "Empirical Research on the Resource-Based View of the Firm: An Assessment and Suggestions for Future Research," Strategic Management Journal, vol. 28. Wiley, pp. 121-146.

20. G. Sanahuja Vélez and G. Ribes Giner, "Effects of Business Internships on Students, Employers, and Higher Education Institutions: A Systematic Review," Journal of Employment Counselling, vol. 52, no. 3, pp. 121-130, Sep. 2015.

21. A. Cipollina et al., "Renewable Energy Desalination: Performance analysis and operating data of existing RES-desalination plants Renewable energy desalination: performance analysis and operating data of existing RES desalination plants," Desalination and Water Treatment, no. August 2016, pp. 1-21, 2014.

22. E. E. Delyannis, "Status of solar assisted desalination: A review," Desalination, vol. 67, no. C, pp. 3-19, Dec. 1987.

23. S. Gorjian, T. T. Hashjin, and B. Ghobadian, "Seawater Desalination using Solar Thermal Technologies: state of the art," pp. 4-7, 2011.

24. R. Semiat, "Present and future," Water International, vol. 25, no. 1, pp. 54-65, Mar. 2000.

25. C. Yamali and I. Solmuş, "Theoretical investigation of a humidification-dehumidification desalination system configured by a double-pass flat plate solar air heater," Desalination, vol. 205, no. 1-3, pp. 163-177, Feb. 2007.

26. E. Tzen and R. Morris, "Renewable energy sources for desalination," vol. 75, pp. 375-379, 2003.

27. S. A. Avlonitis, "Operational water cost and productivity improvements for small-size RO desalination plants," Desalination, vol. 142, no. 3, pp. 295-304, Mar. 2002.

28. K. Ioannis C., "Water desalination cost literature: review and assessment," vol. 223, pp. 1-18, 2008.

29. E. A. S.A., R. Sathyamurthy, and M. M. A., "Improvement of humidification-dehumidification desalination unit using a desiccant wheel," Chemical Engineering Research and Design, vol. 131, pp. 104-116, Mar. 2018.

30. J. Wang, N. Gao, Y. Deng, and Y. Li, "Solar power-driven humidification-dehumidification (HDH) process for desalination of brackish water," Desalination, vol. 305, pp. 17-23, Nov. 2012.

31. J.-J. Hermosillo and C. A. Arancibia-Bulnes, "c," Solar Energy, vol. 86, no. 4, pp. 1070-1076, Apr. 2012.

32. V. Okati, S. Farsad, and A. Behzadmehr, "Numerican analysis of an integrated desalination unit using humidification-dehumidification and subsurface condensation processes," Desalination, vol. 433, pp. 172-185, May 2018. 